\title{
A TRAGÉDIA DOS COMMONS REVISITADA: UMA ANÁLISE CRÍTICA
}

\author{
The tragedy of the commons revisited: a critical analysis
}

Juliano Vargas*

Alain Herscovici**

\begin{abstract}
Resumo: O artigo apresenta a proposta seminal de Hardin (1968) de que o aumento populacional desmedido combinado à propriedade comunal dos bens degenera em problemas de natureza social, não existindo uma solução técnica viável para a questão. Para o autor, o problema apenas pode ser superado com a redução das liberdades individuais e através da coerção, adotando-se o arranjo de propriedade privada ou pública, mas esta última com restrições. Da tese de Hardin, seguida da formalização de seu modelo de acordo com os manuais convencionais de economia, é elaborada uma análise crítica que ressalta os limites dessa abordagem, mostrando que nada indica, sistematicamente, que o arranjo de propriedade privada seja o mais apropriado. A apropriação privada de um bem comum coletivo pode esgotar seu estoque disponível, além do que existem outros meios para regular o sistema e também diferentes situações em função da natureza do bem comum.
\end{abstract}

Palavras-chave: commons; propriedade privada e pública; direitos de propriedade (DP).

\begin{abstract}
The paper presents the seminal proposal of Hardin (1968) that excessive population growth combined with the common property of goods leads to problems of social nature, without a viable technical solution to the question. For the author, the problem only can be overcome by reducing individual freedoms and by coercion, adopting the arrangement of private or public property, with restrictions for the last one. From Hardin's thesis, followed by the formalization of his model according to the conventional manuals of economics, a critical analysis of this approach is elaborated, showing that nothing systematically indicates that the arrangement of private property is the more appropriated. The private appropriation of a collective common good can deplete the available stock, besides there are other ways to regulate the system as well as different situations depending on the nature of the common good.
\end{abstract}

Keywords: commons, private and public property; property rights.

JEL Classification: D71; D23; K11.

Mestre em Economia pela Universidade Federal do Espírito Santo (UFES). Membro do Grupo de Estudos de Macroeconomia (GREM) e do Grupo de Estudos de Economia da Cultura, Comunicação, Informação e Conhecimento (GEECCIC) do Programa de Pós-Graduação em Economia da UFES.

** Doutor em Economia pelas Universidades de Paris I Panthéon-Sorbonne e de Amiens. Coordenador do GREM e do GEECCIC. Professor Titular, Programa de Pós-Graduação em Economia da UFES. 


\section{1 - Introdução}

Este artigo tem como objetivo apresentar um tema específico do problema de social choice ${ }^{1}$, sob uma ótica microeconômica, qual seja, o conflito entre interesses individuais e o bem comum no uso de recursos finitos. As questões básicas que serão discutidas são as seguintes: i) Como ocorre a tragédia dos commons e quais suas implicações? ii) Qual é a solução sugerida por Hardin e pelos manuais convencionais de economia para o problema? iii) Quais são as alternativas e suas respectivas dinâmicas para evitar que ocorra a tragédia dos commons? iv) Por que o sistema de direitos de propriedade privados não se constitui, sistematicamente, como o arranjo mais eficiente?

Quanto ao escopo teórico², a base para a elaboração deste artigo provém de Hardin (1968): da resenha de sua tese seminal sobre a tragédia dos commons, permeada por ponderações julgadas pertinentes. Além disso, o manual de economia de Varian (2003) é importante para o desenvolvimento da análise por formalizar o modelo de Hardin, apresentando uma interpretação econômica de cunho neoclássico.

No que diz respeito à estrutura do artigo, na segunda seção será abordada a proposta de Hardin, suas principais características e as implicações de sua exposição. Na terceira seção, será apresentado o modelo desenvolvido por Varian (2003), seguido de um exemplo prático desenvolvido pelo autor, relativo ao tema. Na quarta seção, com o intuito de enriquecer o debate, será elaborada uma análise crítica a fim de ressaltar os limites da proposta original de Hardin acerca da tragédia dos commons, em um primeiro momento; em um segundo momento, crítica semelhante será feita no que diz respeito à interpretação de Varian.

\section{2 - A tragédia dos commons ${ }^{3}$, de acordo com Hardin (1968)}

\section{1 - Fundamentações teóricas e a questão da maximização}

A argumentação de Hardin perpassa por diversas áreas do conhecimento, tais como: psicanálise, biologia, filosofia, demografia, direito e economia. Todavia, quatro são as correntes teóricas que dão sustentação à tese do autor. A malthusiana, que advoga a hipótese de que as populações humanas crescem em progressão geométrica (exponencialmente), mas os meios de subsistência crescem em progressão aritmética (MALTHUS, 2013). Com recursos finitos, isso significa que a quantia de bens per capita disponível diminui de modo constante. Hardin aceita a suposição resultante de que um mundo com recursos finitos somente pode suportar uma quantidade populacional limitada. A segunda teoria, também aceita por Hardin, é a darwiniana (DARWIN, 1981), composta por dois tópicos: (i) a hereditariedade, que se refere ao conjunto de processos biológicos que asseguram que um ser vivo receba e transmita "caracteres" (contemporaneamente entendidos como informações genéticas) através da reprodução; (ii) a seleção natural, em que características hereditárias favoráveis tornam-se mais comuns em gerações sucessivas de uma população

1 A teoria da escolha social (social choice) estuda como as preferências individuais se agregam para formar uma preferência coletiva. Essa teoria remonta à publicação do paradoxo da votação, por Condorcet (1785). Sua formulação moderna se deve ao teorema da impossibilidade elaborado por Arrow (1951), que buscou elementos da teoria do voto e da economia do bem-estar, generalizando-os. O método consiste em formular um conjunto de axiomas aparentemente razoáveis para a escolha social como requisitos de uma função de bem-estar social para capturar aspectos do problema de agregação e derivar implicações. Os muitos resultados de impossibilidade nos primeiros estudos indicaram que várias premissas (intuitivamente desejáveis) eram incompatíveis entre si.

2 Esta pesquisa é essencialmente teórica, não obstante a mesma abordagem crítica tenha sido aplicada ao estudo de casos concretos, tais como: meio ambiente, recursos naturais, cultura, comunicação, informação e conhecimento. Ver, por exemplo, Hess e Ostrom (2007) e Herscovici (2015).

3 A expressão provém originalmente de uma observação feita pelo matemático amador Lloyd (1833), sobre a posse comunal da terra em aldeias medievais. O conceito foi estendido e popularizado por Hardin no ensaio The Tragedy of the Commons (1968). Todavia, a teoria propriamente dita é tão antiga quanto Tucídides e Aristóteles. 
de organismos que se reproduzem, enquanto características desfavoráveis que são hereditárias tornam-se menos comuns.

Hardin discorda da "mão invisível smithiana"4 no caso da análise demográfica, asseverando que a generalização do laissez-faire ${ }^{5}$ contribuiu para a lógica dominante de que as escolhas individuais levam aos melhores resultados para a sociedade. Isso não vale para o controle populacional, defende o autor, pois levaria à tragédia inevitável de sobreutilização dos recursos e a consequente destruição do homem. Hardin também contesta as formulações de Bentham (BENTHAN, 2005), argumentando que, demograficamente, os objetivos do utilitarismo ${ }^{6}$ e do panóptico ${ }^{7}$ não são razoáveis, por dois motivos: (i) matematicamente não é possível maximizar para duas ou mais variáveis simultaneamente, caso da quantidade ótima populacional e de alimentos; (ii) biologicamente não há como, com recursos finitos, aumentar indeterminadamente a produção de alimentos.

Partindo dessa base teórica, Hardin assevera que a quantidade populacional ótima deve ser menor do que a máxima possível, admitindo que haja dificuldades na definição de um ponto de ótimo, com que se deduz que na abordagem do autor a eficiência social não deve ser avaliada a partir do critério paretiano de justiça ${ }^{8}$-, mas ao contrário, sua análise dá-se em termos de bem-estar social (welfare state), havendo, consequentemente, uma determinação social, e não subjetiva, das externalidades (HERSCOVICI, 2015) ${ }^{9}$. Logo, o bem-estar social a que Hardin se refere é entendido como a igualdade entre o custo marginal privado (CMg Privado) e o custo marginal social (CMg S), o que denota a impossibilidade de agregar utilidades individuais ordinais. Por esse motivo, o autor afirma que a comparação entre diferentes bens é inviável porque eles são incomensuráveis, ou seja, não há como compará-los entre si.

Todavia, o autor alerta que na vida real isso pode ser diferente, como no caso da seleção natural, em que o objetivo atingido depende da ponderação natural das variáveis ${ }^{10}$, ou seja, a escolha individual consiste em comparar a utilidade propiciada por cada bem. Para ele, o homem deveria imitar esse processo, embora até então nenhuma população houvesse conseguido achar seu ponto de ótimo naturalmente ${ }^{11}$, isto é, apresentar um crescimento populacional nulo ou negativo ${ }^{12}$.

\section{2 - A tragédia da liberdade dos commons e a importância da legislação}

4 Termo utilizado por Adam Smith em seu livro, A Riqueza das Nações (1776), para descrever como em uma economia de mercado, apesar da ausência de convergências entre os interesses individuais e o interesse geral, a interação dos indivíduos parece resultar em uma determinada ordem, como se houvesse uma "mão invisível" que os orientasse.

5 É parte da expressão "laissez-faire, laissez-aller, laissez-passer", que significa literalmente "deixe fazer, deixe ir, deixe passar". Laissez-faire é uma expressão-símbolo do liberalismo, sendo o liberalismo uma filosofia política que tem como fundamento a defesa da igualdade e da liberdade individual nos campos econômico, político, religioso e intelectual, do direito de propriedade privada e da supremacia do indivíduo frente ao poder estatal.

6 Nas Ciências Econômicas, o utilitarismo é entendido como um princípio segundo o qual: (a) os agentes maximizam funções de utilidade e /ou de lucro; (b) sua atuação corresponde a uma situação de maximização a partir do critério de Pareto.

7 Projeto de prisão circular, em que um observador central pode ver todos os locais onde há prisioneiros. Esta lógica poderia ser utilizada em todas as esferas da sociedade, como meio de tornar mais eficiente seu funcionamento. Hardin (1968) refuta essa concepção, pois seriam necessárias outras pessoas para vigiar àqueles que estariam vigiando e outros para vigiar os últimos e assim sucessivamente, inviabilizando esse mecanismo.

8 "Em termos de justiça redistributiva, o critério de Pareto é relativo, à medida que ele corresponde a um processo de maximização, para uma distribuição de renda determinada exogenamente” (HERSCOVICI, 2013, p. 197).

9 Nesse sentido, Coase ressalta o fato de que a definição das externalidades entra em contradição com a teoria subjetiva do valor. Assim, "à medida que a determinação das externalidades é institucional, essas não dependem da avaliação subjetiva dos consumidores/usuários” (HERSCOVICI, 2015, p. 11). Ver Coase (1960).

10 Como exemplo concreto, pode-se pensar em uma espécie qualquer em seu habitat natural. Dependendo do contexto, é melhor ser pequeno e bem camuflado, enquanto em outros, é melhor ser grande e poderoso (HARDIN, 1968).

11 Dado que esse fenômeno já ocorreu inúmeras vezes por conta de catástrofes naturais e de guerras.

12 Atualmente esse fenômeno já é uma realidade concreta em vários países, resultante da elevação da expectativa de vida aliada a baixos índices de natalidade. 
Posicionado teoricamente, o autor descreve objetivamente a tragédia dos commons:

Picture a pasture open to all. It is to be expected that each herdsman will try to keep as many cattle as possible on the commons. Such an arrangement may work reasonably satisfactorily for centuries because tribal wars, poaching, and disease keep the numbers of both man and beast well below the carrying capacity of the land. Finally, however, comes the day of reckoning, that is, the day when the long-desired goal of social stability becomes a reality. At this point, the inherent logic of the commons remorselessly generates tragedy (HARDIN, 1968, p. 1244).

Como ser maximizador, o criador de gado se pergunta qual a vantagem de adicionar vacas ao seu rebanho. Seu ganho dá-se ao incrementá-lo com uma vaca, com todo o lucro - deduzidos os custos - revertido para si. Assim, "the positive utility is nearly +1 ". Mas esse incremento de uma vaca ao pasto já superpovoado gerará pequena perda para todos, inclusive para si. Logo, "the negative utility for any particular decision making herdsman is only a fraction of -1 "13 (HARDIN, 1968, p. 1244). Adicionando as utilidades, a conclusão racional é aumentar seu rebanho ilimitadamente, em um espaço limitado. Aí estaria a tragédia, pois a racionalidade individual não é compatível com os commons limitados. A liberdade dos commons seria a ruína de todos. O autor cita casos em que o problema foi contornado, como na agricultura, e exemplos em que a questão dos commons não havia sido resolvida, como no caso da pesca em alto-mar. Isso o leva a indagar sobre o que deveria ser feito, devendo-se optar pela solução de propriedade privada ou pela solução de propriedade comunal que, no segundo caso, requereria regras jurídicas bem definidas de acesso e uso.

Em outro exemplo, a tragédia dos commons aparece como o problema da poluição, mas de forma reversa, pois suja-se “our own nest”, sendo também consequência do aumento populacional. As questões consideradas são os casos de esgotos, químicos, entre outros, nocivos ao meio ambiente. A lógica é semelhante a anterior, em que o homem - maximizador - considera que seu ganho ao eliminar resíduos em uma situação dos commons é inferior ao custo de sua esterilização antes do descarte final $^{14}$ (HARDIN, 1968, p. 1245).

\section{3 - A liberdade para procriar e a questão da consciência}

Na tragédia dos commons, Hardin aborda a questão populacional de modo distinto, comparando a seleção natural - que controla a fecundidade - com o que ocorre com os seres humanos, comprometidos com o bem-estar social, questionando os interesses de certos grupos que têm a alta taxa de reprodução como política para assegurar seu espaço na sociedade. Para ele, "to couple the concept of freedom to breed with the belief that everyone born has an equal right to the commons is to lock the world into a tragic course of action" (HARDIN, 1968, p. 1246). Destaca que é exatamente isso o que preconiza a Organização das Nações Unidas ${ }^{15}$, sobretudo por meio da Declaração Universal dos Direitos Humanos (UNITED NATIONS, 1948), por sustentar que qualquer decisão sobre o tamanho de determinada família deve ser irrevogavelmente tomada exclusivamente pela mesma. O autor rechaça esse posicionamento, concebendo a questão nos termos propostos por Kingsley, ou seja, de que o planejamento familiar da população em escala mundial é a opção mais apropriada (KINGSLEY, 1967).

Hardin, baseando-se na concepção darwiniana de hereditariedade, argumenta não ser possível controlar a reprodução das pessoas no longo prazo por meio de um apelo à consciência, pois

13 No primeiro caso há externalidade positiva de oferta e, no segundo caso, externalidade negativa de oferta.

14 Como se pode observar, a questão dos commons permite inúmeras aplicações. Todavia, neste artigo tomar-se-á o caso específico do criador de gado como exemplo representativo geral a ser pormenorizado.

15 Organização internacional, cujo objetivo é facilitar a cooperação em matéria de direito internacional, segurança internacional, desenvolvimento econômico, progresso social, direitos humanos e a realização da paz mundial. 
people vary. Confronted with appeals to limit breeding, some people will undoubtedly respond to the plea more than others. Those who have more children will produce a larger fraction of the next generation than those with more susceptible consciences. The difference will be accentuated, generation by generation (HARDIN, 1968, p. 1246).

O autor presume que novas gerações herdem geneticamente, em boa parte, as características morfológicas e também relativas à personalidade ${ }^{16}$. Esse raciocínio serve tanto para a questão populacional quanto para qualquer instância em que a situação dos commons estiver presente no longo prazo. Como frisa o autor, "to make such an appeal is to set up a selective system that works toward the elimination of conscience from the race" (HARDIN, 1968, p. 1246). Ainda sobre o apelo à consciência, dessa vez com referência ao curto prazo e no âmbito da psicanálise, o autor aponta que em algum momento surgem também desvantagens, como informações contraditórias ou duas situações distintas (o chamado “double bind”) (BATESON et al, 1956), a saber:

i) informação pretendida: caso em que a pessoa não atende ao apelo à consciência, tendo assim sua atitude socialmente e abertamente reprovada por não agir de modo responsável;

ii) informação não pretendida: a pessoa atende a esse apelo, mas é condenada de modo velado por ser tola e envergonhar-se diante da sua escolha enquanto outras exploram a situação dos commons.

Destarte, Hardin afirma que apelar à consciência das pessoas é tentador aos que querem estender seu controle além da legalidade, gerando sentimentos de culpa potencialmente patogênicos naqueles que não cooperam. Portanto, o autor é contrário a esse tipo de política de intimidação que tenta deturpar, em nome da consciência, o real sentido da palavra responsabilidade, qual seja, "the product of definite social arrangements" (FRANKEL ${ }^{17}$, apud HARDIN, 1968, p. 1247).

\section{4 - Princípio da coerção e o reconhecimento da necessidade}

Quanto aos custos de monitoramento em relação ao free rider $^{18}$, Hardin explica que os arranjos sociais que resultam em responsabilidade são àqueles que criam um dispositivo coercitivo de alguma sorte, como a possibilidade de ser multado, por exemplo ${ }^{19}$. A dita temperança ${ }^{20}$ pode resultar da coerção, sem esta última ter uma conotação necessariamente negativa, pelo fato de nesse caso ser recíproca e acordada mutuamente pelas pessoas afetadas. Mesmo uma solução indesejável no sentido de que obviamente não se quer pagar multas e ter outros meios coercitivos atuantes, ela pode, segundo o autor, auxiliar as pessoas de pouca consciência a se enquadrarem ao objetivo a ser atingido, escapando do problema dos commons. Se ainda assim os comportamentos oportunistas persistirem, o autor sugere a aplicação da legislação correspondente vigente, com temperança.

Hardin reconhece que esta pode não ser a alternativa perfeita, mas ainda assim ela é preferível frente à potencialmente ruína dos commons. Conclui que a instituição da propriedade privada combinada com a tradição e heranças jurídicas é a solução mais adequada nesse contexto. Explica

16 A parte relativa às características de personalidade está ligada a condições que não se referem ao corpo (“exosomatically", de acordo com o termo empregado no texto original).

17 Ver Frankel (1955).

18 A literatura econômica define o comportamento oportunista (free rider) como àquele em que um ou mais agentes econômicos acabam usufruindo de um determinado benefício proveniente de um bem, sem que tenha havido uma contribuição para sua obtenção.

19 Imagine o caso em que "to keep downtown shoppers temperate in their use of parking space we introduce parking meters for short periods, and traffic fines for longer ones. We need not actually forbid a citizen to park as long as he wants to; we need merely make it increasingly expensive for him to do so. Not prohibition, but carefully biased options are what we offer him. A Madison Avenue man might call this persuasion; I prefer the greater candor of the word coercion" (HARDIN, 1968, p. 1247). Cabe ressaltar que, em termos econômicos, esta é uma descrição típica de exclusão pelos preços.

20 Temperança no sentido de sobriedade, equilíbrio e parcimônia. 
que a implementação dessa solução exige apenas sua aceitação democrática majoritária como a melhor opção dentre as disponíveis, mesmo que seja imperfeita e/ou injusta. Nesse caso, abster-se de agir (manter o status quo) é considerada uma ação, podendo ser danosa. Para ele, "we can make a rational decision which will not involve the unworkable assumption that only perfect systems are tolerable” (HARDIN, 1968, p. 1248).

Hardin sintetiza seu posicionamento em relação à questão dos commons destacando que ele somente é justificável quando há baixa densidade populacional. Alerta para o fato de que com o crescimento da população, os commons têm abandonado sua condição progressivamente em diversos segmentos, tais como: em termos alimentares, cercando terrenos agrícolas e restringindo seu uso; eliminação de resíduos, como esgotos; além do desafio de avançar efetivamente no que concerne à poluição causada pelos automóveis, fábricas, energia atômica, entre outros. Hardin avalia ser inevitável que cada nova restrição (enclosure) aos commons envolva a violação da liberdade pessoal (HARDIN, 1968, p. 1248).

Para o autor, o aspecto mais importante do reconhecimento da necessidade nesse contexto é a assunção de que não é possível conciliar o aumento populacional progressivo com a propriedade comunal, pois não há solução técnica viável que evite o desastre da superpopulação, que trará a ruína para todos. Aponta também que há um receio de tomar decisões mais firmes, porém necessárias, cedendo ao apelo para a consciência e para a responsabilidade das pessoas, o que é prejudicial tanto no curto quanto no longo prazo. Por fim, o autor afirma que

\begin{abstract}
the only way we can preserve and nurture other and more precious freedoms is by relinquishing the freedom to breed, and that very soon. "Freedom is the recognition of necessity" 21 - and it is the role of education to reveal to all the necessity of abandoning the freedom to breed. Only so, we can put an end to this aspect of the tragedy of the commons (HARDIN, 1968, p. 1248).
\end{abstract}

De um modo geral, esta foi a visão seminal de Hardin sobre a questão dos commons, apresentada em forma de resenha, expondo a interpretação desse autor acerca do tema. Falta apresentar a leitura dos manuais convencionais de microeconomia ao caso proposto por Hardin, bem como uma análise crítica dessa lógica de pensamento, objetivos a serem perseguidos nas seções seguintes.

\title{
3 - A tragédia do uso comum, de acordo com os manuais convencionais de microeconomia
}

\section{1 - A tragédia do uso comum}

Apreciado exclusivamente sob o prisma econômico, Varian (2003) apresenta seu enfoque ao problema dos commons. Inicia sua abordagem esclarecendo que se os direitos de propriedade forem bem definidos, não haverá problemas relativos a externalidades. Caso contrário, o resultado das interações econômicas apresentará ineficiências, como a tragédia do uso comum. Contrapondo essa visão, Barzel (1997) afirma que o sistema de DP não é plenamente eficiente: o controle necessário dos free riders implicam em custos de transação positivos. Essas imperfeições decorrem: (i) da natureza econômica dos bens; (ii) dos comportamentos dos agentes. Isto faz com que os DP não possam ser plenamente eficientes e que os custos necessários para implementar esses DP sejam obrigatoriamente positivos (custos de monitoramento), simultaneamente, pelas diferentes assimetrias

21 Hardin evoca um conceito do filósofo Hegel denominado de "espírito objetivo" - referente às concretizações da sociedade e dividido em três graus dialéticos: o direito, a moralidade e a moralidade social - para justificar a restrição à liberdade. Todavia, cabe ressaltar que na realidade a paráfrase foi proferida por Friedrich Engels, portanto, a partir da interpretação pessoal deste sobre os escritos de Hegel, sendo discutível se está integralmente de acordo com a mensagem original. $\mathrm{O}$ que se pode assumir é que tanto Engels como Hardin tinham uma concepção hegeliana de Estado. Ver Mayos (2007). 
da informação e pelo caráter não ergódigo do universo (ARROW, 1974; BARZEL, 1997; HERSCOVICI, 2013).

Tomando como ponto inicial o exemplo de ineficiência descrito seminalmente por Hardin, qual seja, o de um vilarejo agrícola com gado em campo comunitário, Varian (2003) explicita sua interpretação peculiar do caso em questão. Primeiramente, Varian (2003) especifica que a intenção é a de comparar dois mecanismos de alocação, a saber:

i) solução de propriedade privada, em que alguém possui o campo e decide quantas cabeças de gado devem pastar ali;

ii) solução em que o campo é de propriedade comunal dos moradores do vilarejo e o acesso a ele é livre e irrestrito ${ }^{22}$. Nota-se que aqui não se identifica o princípio da coerção.

O modelo desenvolvido por Varian considera as seguintes hipóteses:

i) $a$ corresponde ao custo de uma vaca;

ii) a quantidade de leite que a vaca produzirá vai depender de quantas outras vacas pastam na terra comunal;

iii) $f(c)$ corresponde ao valor do leite produzido se houver $c$ vacas pastando na terra. Então, o valor do leite por vaca é igual ao produto médio, $f(c) / c$.

A partir destas hipóteses, propõe-se a seguinte questão: quantas vacas pastariam na terra comunal se quiséssemos maximizar a riqueza total do vilarejo? Para respondê-la, Varian (2003) monta o seguinte problema:

$$
\max f(c)-a c
$$

Assim, a produção máxima ocorrerá quando o produto marginal de uma vaca (PM (c*)) for igual ao seu custo, $a$ :

$$
P M\left(c^{*}\right)=a
$$

Nesse caso, se o produto marginal de uma vaca for maior do que $a$, vale a pena adicionar uma ao pasto. Se o campo de pastagem comum fosse propriedade de alguém que pudesse restringir o acesso a ele, seria esse o resultado. Desse modo, o proprietário do pasto autorizaria seu uso para um número exato de vacas que maximizasse a quantidade de leite a ser produzida por cada uma (maximização da produção total e minimização dos custos necessários a sua implementação), impondo um mecanismo de exclusão pelos preços (ALCHIAN; DEMSETZ, 1972). Para Herscovici (2013, p. 195), esse mecanismo é determinado "a partir do sistema de DP vigente; no caso de um sistema de DP privado, a exclusão se concretiza pelos preços que condicionam o consumo individual, ou seja, o acesso ao estoque disponível”.

Na sequência, Varian indaga sobre o que aconteceria se os habitantes do vilarejo decidissem usar ou não o campo comum. Cada habitante tem a escolha de criar ou não uma vaca leiteira, e será lucrativo fazê-lo enquanto a produção gerada pela vaca for maior do que o custo do animal. Supondo

22 É necessário frisar que, diferentemente do entendimento preconizado por Varian (2003), a concepção de propriedade comunal não implica ausência de direitos privados, podendo ocorrer, por exemplo, cedência parcial desses direitos a fim de criar um bem público. Ver Cox (1986), Ostrom (2000) e Hess; Ostrom (2007). 
que $c$ vacas estejam sendo criadas, de modo que a produção atual por cabeça seja de $f(c) / c$. Quando um habitante do vilarejo pensa em colocar mais uma vaca, a produção total será de $f(c+1)$ e o número total de cabeças de gado será de $c+1$. Portanto, a receita que a vaca gera para o habitante do vilarejo será de $f(c+1) /(c+1)$. Ele tem de comparar essa receita com o custo da vaca, $a$. Se $f(c+$ $1) /(c+1)>a$, é lucrativo adicionar a vaca, já que o valor da produção excede o custo. Portanto, os habitantes do vilarejo escolherão criar mais gado até que o produto médio por cabeça seja igual a $a$. Segue-se que o número total de cabeças de gado criadas será de $\hat{c}$, em que

$$
{ }_{\hat{c}}^{f(\hat{c})}=a .
$$

Outra forma de chegar a esse resultado, segundo Varian (2003), é permitir o acesso (entrada) livre. Se for lucrativo criar uma vaca no pasto comunitário, os habitantes do vilarejo comprarão gado. Eles só pararão de adicionar cabeças de gado a esse pasto quando os lucros marginais forem zero, ou seja, quando

$$
f(\hat{c})-a \hat{c}=0,
$$

o que é apenas um rearranjo da condição do parágrafo anterior.

Ao definir ou não a compra de uma vaca, o indivíduo observa o valor extra que obterá, $f(c) / c$, e compara isso ao custo de uma vaca leiteira, $a$. lsso é importante, mas o que ele deixa de avaliar em seu cálculo é o fato de que sua vaca diminuirá a produção média de leite de todas as outras. Como ele ignora o custo social de sua compra, haverá vacas em excesso no pasto comum, pois se pressupõe que cada indivíduo tenha um número de cabeças de gado negligenciável em relação à quantidade criada no campo comunitário.

\section{Gráfico 1 - A tragédia do uso comum, com solução de propriedade privada}

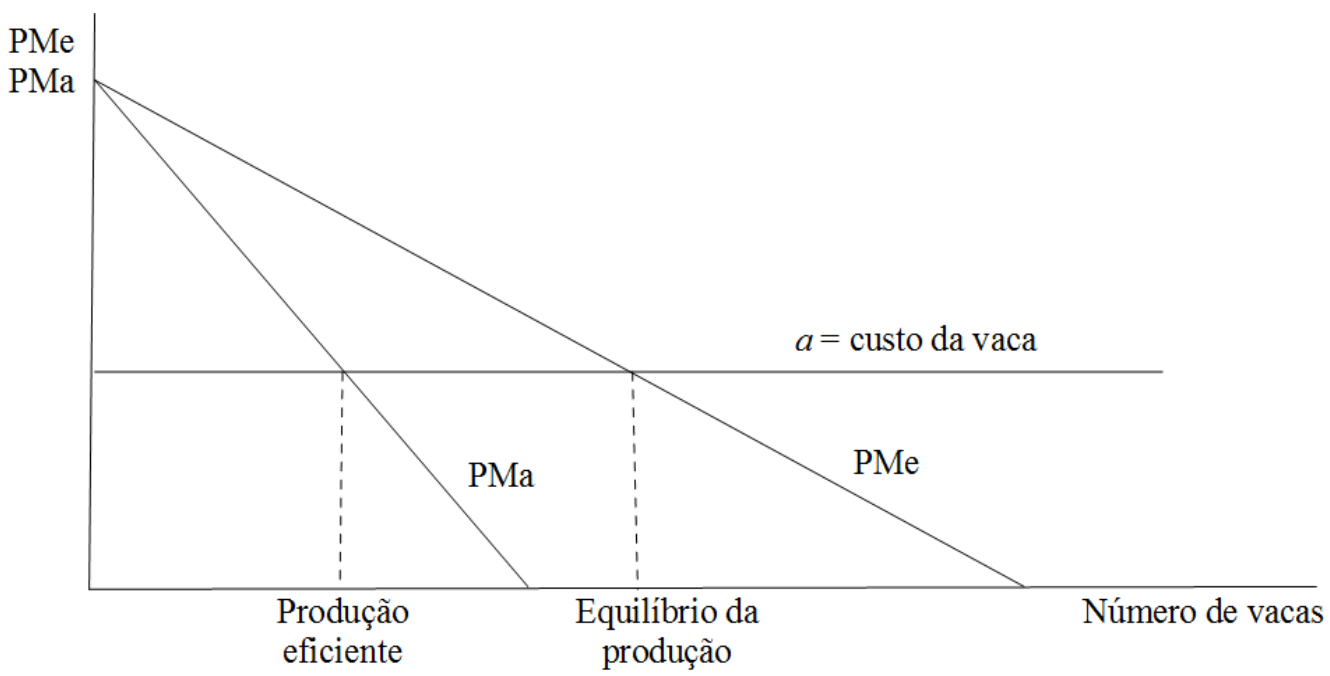

Fonte: Varian, 2003, p. 690.

Esse argumento é ilustrado no gráfico acima. Nele, é representada uma curva de produto médio (PMe) decrescente, pois a produção por unidade decresce à medida que um número maior de vacas for criado no pasto comum. Como o produto médio é decrescente, a curva de produto marginal (PMa) tem de situar-se sempre abaixo da curva de produto médio. Portanto, o número de vacas no caso em que o produto marginal é igual a $a$ tem de ser menor do que no caso em que o produto médio é igual a $a$. O pasto comum ficará superlotado se não houver um mecanismo que restrinja seu uso. 
a propriedade privada fornece tal mecanismo. De fato, se tudo com que as pessoas se preocupam for propriedade de alguém que possa controlar seu uso e, em especial, pode impedir que outros a utilizem de maneira excessiva, então não haverá, por definição, externalidades. A solução de mercado leva a um resultado eficiente no sentido de Pareto. As ineficiências só podem resultar de situações em que não há meio de impedir que outros utilizem alguma coisa (VARIAN, 2003, p. 689).

Todavia, no exemplo específico das vacas com solução de propriedade privada, evidenciam-se dois problemas teóricos: (i) a quantidade de vacas, no mecanismo apontado por Varian, é uma variável endógena; (ii) para Hardin e Varian, o custo da vaca é constante, ou seja, não há retornos decrescentes à la Ricardo (RICARDO, 2004, 2012; HERSCOVICI, 2014). Tanto Hardin quanto Varian consideram, erroneamente, que é preciso diminuir a quantidade de vacas para voltar à posição que corresponde à maximização em termos de bem-estar social. Entretanto, a lei dos retornos decrescentes se explica a partir de uma causa econômica, e não física (SRAFFA, 1925, p. 37); a escassez é, por natureza, social, e é causada pelas diferentes evoluções sociais e econômicas. A escassez aparece em função do aumento exógeno da produção. Esta escassez explica, por sua vez, o aumento dos custos e a queda da produtividade (HERSCOVICI, 2014). Sendo assim, diminuir a quantidade de vacas pode resultar em carestia.

Já no caso da teoria da renda diferencial Ricardo, a taxa de crescimento da população ativa é uma variável exógena que os produtores não controlam. $\mathrm{Na}$ análise ricardiana é estabelecida uma relação causal em que a escassez da terra determina a propriedade privada desta, não sendo possível deduzir a lei da produtividade marginal decrescente que embasa os argumentos de Hardin e de Varian. De acordo com o modelo ricardiano (alheio ao critério de Pareto), a propriedade privada das terras não permite resolver o problema. O único resultado da solução proposta por Hardin e por Varian nesse contexto é a elevação do custo médio de produção, na medida em que o aumento da escala de produção implica em queda da taxa de lucro (RICARDO, 2012; HERSCOVICI, 2014).

O progresso técnico e/ou eventualmente a modificação inicial da distribuição da renda gera a escassez da terra, o que leva a DP privados das terras de melhor qualidade, permitindo o aparecimento e o aumento das partes relativas à renda e aos salários no produto. Por fim, esse contexto acaba em uma diminuição da parte relativa aos lucros da renda, ou seja, a escassez das terras de melhor qualidade explica o aparecimento e o aumento da renda da terra. A análise a partir da perspectiva ricardiana demonstra que os preços não divulgam a totalidade da informação. Logo, conclui-se que "a escassez é, por natureza, social, e é causada pelas diferentes evoluções sociais e econômicas”, isto é, a escassez social explica o lucro e a renda. (HERSCOVICI, 2014, p. 15).

Mais apropriado do que o proposto por Varian (2003), para o caso do uso dos recursos de propriedade comunal, é a solução elaborada por Pindyck; Rubinfeld $(2010)^{23}$. Supõe-se que a quantidade de leite produzida é suficientemente pequena em relação à demanda, fazendo com que 0 preço do leite seja dado. Além disso, supõe-se que há alguém que controle o número de proprietários com acesso a pastagem. O número eficiente $v^{*}$ de vacas introduzidas no pasto em um dado período é determinado no ponto em que o benefício marginal (BMg) de adicionar uma vaca é igual a seu custo marginal social (CMg S). O BMg é o preço obtido na curva de demanda. O CMg S inclui não só os custos operacionais privados, mas também o custo social do esgotamento do estoque disponível de pasto. A solução seria a propriedade privada, em que um único proprietário estabelecerá um preço para a utilização do recurso que seja igual ao custo marginal do esgotamento do estoque de pasto (CMg privado 2). Ao se defrontar com esse preço, os produtores que compõem o agregado não acharão lucrativo inserir um número de vacas superior a $v^{*}$. Contudo, como essa solução é

23 Originalmente, Pindyck; Rubinfeld (2010) utilizam o exemplo de um grande lago com peixes. Houve uma adaptação desse exemplo ao caso apresentado por Varian (2003), sem alterações no que se refere ao resultado final obtido e/ou sua aplicação. 
geralmente inviável, pode ser necessário que os recursos sejam de propriedade comunal ou então que sejam diretamente regulamentados pelo governo (PINDYCK; RUBINFELD, 2010).

\section{Gráfico 2 - A tragédia do uso comum, com solução de propriedade comunal}

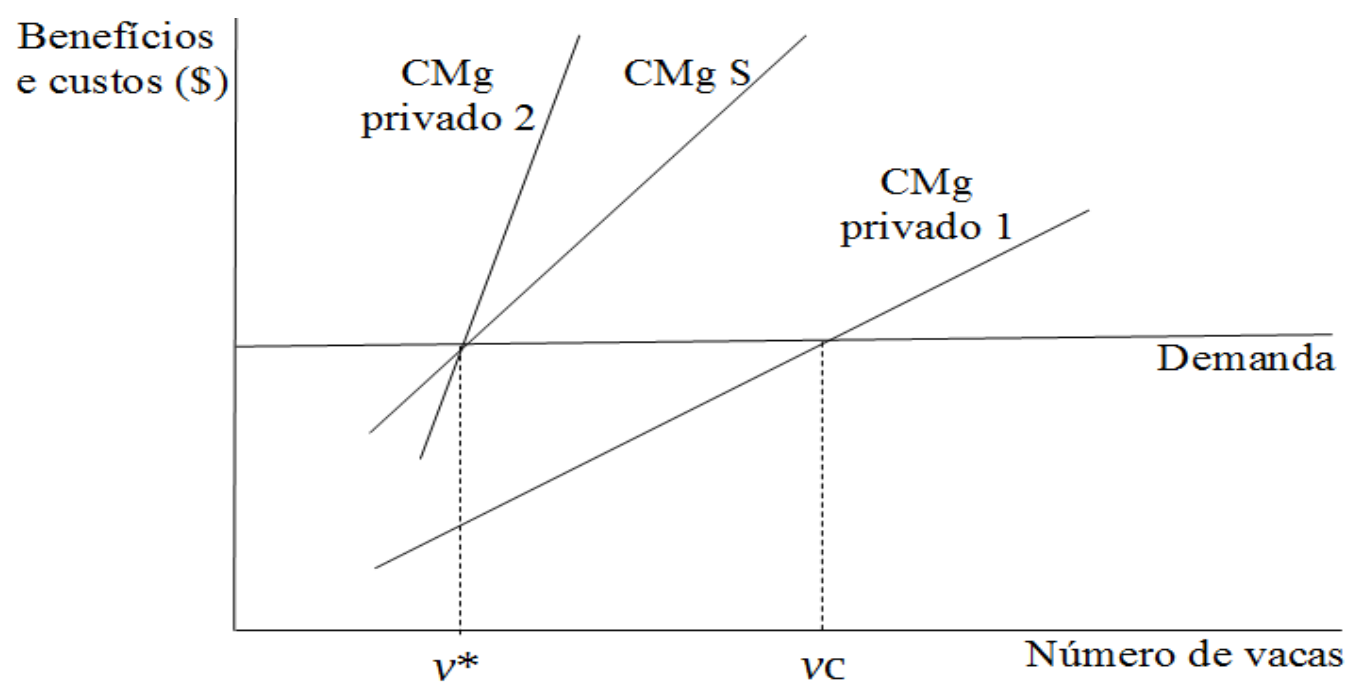

Fonte: Adaptado de Pindyck; Rubinfeld (2010, p. 574).

Quando um recurso de propriedade comunal, como a pastagem, é acessível a todos, o recurso é usado até o ponto $v c$, no qual o custo marginal privado 1 (CMg privado 1) é igual ao retorno adicional gerado. Esse uso excede o nível eficiente $v^{*}$, no qual o CMg S de usar o recurso é igual ao BMg (como mostrado pela curva da demanda). Com a regulação da atividade - limitando o acesso a elas ou restringindo seu uso - é possível manter o uso ao nível eficiente $\mathrm{v}^{*}$, igualando o $\mathrm{CMg} \mathrm{S}$ ao CMg privado 2.

\section{4 - Análise crítica à proposta da tragédia do uso comum}

\section{1 - Os limites da análise de Hardin}

Objetivamente, como visto, para os casos que envolvem bens comuns em uma determinada coletividade (componentes ecológicos, recursos naturais, conhecimento comum, entre outros), Hardin propõe a apropriação privada destes como uma solução para evitar o problema dos commons, pois do contrário pode haver esgotamento do estoque disponível.

Deve-se levar em consideração que, conforme Herscovici (2013), Hardin analisa a questão dos commons para o contexto do antigo regime inglês, ainda do século XVIII, explicando o fracasso da propriedade comum da terra pela ausência de um sistema institucional capaz de preservar o estoque de bem comum. Porém, presentemente há limites para esta tese, a saber:

i) no caso da apropriação privada dos recursos que derivam do bem comum, existem outros meios para regular o sistema, como as convenções e regras explícitas e/ou implícitas no caso das diferentes coletividades, que determinam e controlam as diferentes modalidades de apropriação social desses bens. Isso possibilita o controle dos comportamentos oportunistas, minimizando assim as implicações ligadas a tais comportamentos para um nível de custos compatível com o funcionamento do sistema (OSTROM, 2000). Contrariamente ao exposto por Hardin, as restrições (enclosures) se explicam a partir da atuação dos fazendeiros mais ricos, isto é, a partir do desrespeito das regras que regulavam as modalidades de apropriação privada deste bem comum (COX, 1986). Constata-se que o fato de ser comunal não implica obrigatoriamente que haja liberdade irrestrita sobre o uso do bem comum, pois 
o simples fato de existirem convenções e regras pode ser suficiente para não incorrer em sua sobreutilização, não sendo necessária coerção de qualquer tipo para evitar o sobreuso;

ii) é preciso, igualmente, diferenciar as situações em função da natureza econômica do bem comum. Quando os recursos obtidos do bem comum são bens privados divisíveis, os benefícios consumidos por um indivíduo é subtraído dos benefícios disponível a outros (OSTROM, 2000). De fato, a explicação de Hardin só faz sentido no caso dos bens serem privados e totalmente divisíveis, como no exemplo da quantidade de leite a ser produzida por cada vaca, descrito por Varian (2003), por exemplo. Quando, ao contrário, trata-se de bens públicos distribuídos no seio de redes, em que qualitativamente os serviços são indivisíveis, a utilidade (externalidade positiva) de cada consumidor/usuário depende diretamente da quantidade e da "qualidade" total de consumidores/usuários. Essas externalidades correspondem à criação de utilidade social e ressaltam a interdependência generalizada das funções de utilidade individuais. No caso das redes eletrônicas, as externalidades de demanda (ou de consumo), definidas pelo fato da função de utilidade de um indivíduo depender do consumo de outros indivíduos ou da produção das firmas, expressam esta relação ${ }^{24}$ (KATZ; SHAPIRO, 1985, HERSCOVICI, 2010). Pode-se observar a existência deste tipo de externalidade na indústria de softwares e nos sistemas de compartilhamento de arquivos digitais. Na presença de bens públicos, as modalidades de apropriação privada desses bens provocam falhas de mercado significativas, com a exclusão através dos preços levando à diminuição do número de participantes e da qualidade indivisível do serviço disponível para o conjunto da comunidade (HERSCOVICI, 2007a). Essa situação impõe uma limitação das externalidades positivas e da taxa de crescimento da produção, de acordo com o exemplo da privatização dos scientific commons ${ }^{25}$ (NELSON, 2003). Não se trata mais de uma concorrência pelos preços que os consumidores/usuários têm que pagar, mas de processos complexos de internalização das diferentes externalidades de redes geradas no seio do sistema. Há uma valorização econômica das modalidades de acesso à rede, em que cada usuário contribui à criação de valor sob a forma de utilidade social; trata-se de endogeneizar as externalidades de redes assim criadas, a partir de um processo de two-sided markets ${ }^{26}$ (HERSCOVICI, 2010, p. 1);

iii) para o exemplo dos commons, há o contraexemplo dos anticommons, que ocorre quando os indivíduos racionais (agindo separadamente) desperdiçam coletivamente um recurso, subutilizando-o. Isto acontece quando demasiado número de indivíduos possuem direitos de exclusão (como direitos de propriedade) sobre determinado recurso escasso. Os anticommons se caracterizam pelo fato do conhecimento ser o objeto de DP intelectual múltiplo (HELLER; EISENBERG, 1998); nesse caso as regras de mercado também produzem externalidades negativas e consideráveis falhas de mercado. Há uma intensificação dos direitos de propriedade relativos à aquisição dos diferentes processos necessários à implementação de uma determinada tecnologia, à medida que os usuários têm de negociar esses direitos com vários titulares dos direitos. Este mecanismo se aplica perfeitamente ao capital intangível, mais especificamente aos DP intelectual: a tragédia dos anticommons mostra claramente que os custos de acesso à tecnologia não são, sistematicamente, minimizados a partir de um sistema de DP intelectual privado. Ao contrário, a privatização do conhecimento pode bloquear a dinâmica cumulativa de sua produção (HELLER; EISENBERG, 1998; NELSON, 2003; HERSCOVICI, 2012a).

24 Existe também a externalidade relacionada à oferta (ou produção), definida pelo fato da função de produção de uma firma depender do consumo final ou da produção de outras firmas (BENARD, 1985). As externalidades de oferta se relacionam com o fato dos agentes internalizarem as diferentes externalidades geradas pelo sistema (no caso de ela ser positiva), ou, ao contrário, de não poderem internalizar as externalidades que eles mesmos criaram (no caso de ela ser negativa) (HERSCOVICI, 2010).

25 A expressão scientific commons diz respeito ao fato de grande parte da ciência ser baseada na produção pública de pesquisas, sendo que o conhecimento gerado por esses estudos é amplamente de livre acesso e disponível a outros potenciais pesquisadores (NELSON, 2003).

26 Também conhecido como two-sided networks, refere-se à valorização relativa ao acesso à rede, e não mais diretamente do usuário/consumidor final. 
Exemplificando, suponhamos que para determinado processo tecnológico há dois titulares de DP intelectual, $A$ e $B$. Se $A$ diminui o preço relativo à aquisição de direitos, a demanda dos DP intelectual de $A$ vai aumentar; a demanda dos DP intelectual de $B$ vai aumentar também, mesmo se $B$ não diminuir seus preços. A existência de externalidades de demanda ressalta as falhas de coordenação que estão surgindo nesse mercado e o equilíbrio sub-ótimo que lhe é ligado. Nesse exemplo, $A$ não tem interesse em baixar seu preço se $B$ mantém seu preço constante; não haverá queda dos preços dessas patentes. Em todos os casos, haverá uma sub-aditividade dos custos relativos à aquisição desses direitos, na medida em que o preço necessário para utilizar aquela tecnologia será superior àquele que prevaleceria no caso de haver apenas um detentor de direito. Finalmente, no caso de haver um patrimônio comum ao conjunto dos agentes (meio ambiente, conhecimento aberto, entre outros), o fato de um agente se apropriar, no âmbito de uma lógica privada, de parte desse estoque diminui o nível do estoque disponível para os outros agentes. Esse comportamento predador só pode gerar uma diminuição do patrimônio comum ao conjunto dos agentes; à medida que essas atividades são cumulativas e sequenciais, isto ocasiona uma diminuição da taxa de crescimento das inovações e das invenções (HERSCOVICI, 2007b, p. 400-401).

A modificação da natureza econômica dos bens e dos serviços tornam necessárias modificações radicais do sistema de DP intelectual: a existência de novas formas de propriedade intelectual é reveladora deste tipo de evoluções. Por sua vez, este "afrouxamento" do sistema de DP intelectual se explica pelo fato dos contratos não serem completos e da racionalidade dos agentes não ser substantiva: nessas condições, os custos são por natureza, importantes, e a regulação (ou modalidade de governança) adequada não corresponde mais, sistematicamente, à regulação de mercado, da maneira como ela é definida pela análise neoclássica padrão. Assim sendo, a determinação de um sistema de DP intelectual deve ser uma escolha institucional que deve ser compatível com as modalidades de governança e com a natureza dos bens e dos serviços (HERSCOVICI, 2007b, 2010).

De acordo com Alchian e Demsetz (1973), a tragédia dos commons se explica a partir da contradição entre a ausência de propriedade, no que diz respeito ao estoque de bens comuns, e a apropriação privada dos bens. Se, por exemplo, o resultado da atividade fim for dividido igualmente entre os diferentes membros da comunidade, independentemente das contribuições individuais, não haveria comportamentos oportunistas. A apropriação privada de um bem público, ou semipúblico, explica a existência e o desenvolvimento dos comportamentos oportunistas.

Há dois modos de controlar, ou de eliminar parcialmente, esses comportamentos oportunistas: ou eliminar os DP privados, no que se refere ao consumo, ou, ao contrário, privatizar a propriedade do bem comum. O primeiro caso diz respeito a formas de economia cooperativa (nas quais a apropriação privada não é determinada a partir da contribuição individual de cada agente, mas em função de outros princípios de redistribuição ${ }^{27}$ ) ou em situações em que a propriedade do bem público é coletiva. O segundo caso corresponde à privatização do estoque de bem comum, em que a preservação deste estoque será assegurada a partir do comportamento "racional” do proprietário privado: a exclusão pelos preços leva a eliminação dos comportamentos oportunistas.

Determinada modalidade de governança será escolhida, em relação a um mesmo nível de produção, a partir do nível dos custos relativos a cada uma dessas modalidades. Contudo, este nível dos custos depende diretamente da natureza econômica dos bens e do sistema de DP vigente, em que no caso de um sistema de direitos de propriedade privado, a exclusão ocorre por meio dos preços que regulam o consumo individual, isto é, o acesso ao estoque disponível (HERSCOVICI, 2013), similarmente ao descrito na seção anterior.

27 Para Herscovici (2013, p. 6), “isto corresponde ao funcionamento das redes de compartilhamento de arquivos, às modalidades de produção e de distribuição dos programas livres e aos scientific commons”. 


\section{2 - Os limites da análise de Varian}

Analogamente à Hardin, porém com um enfoque estritamente econômico, o manual de microeconomia de Varian (2003) aponta, como exposto na terceira seção, que se os direitos de propriedade forem bem definidos, não haverá problemas relativos às externalidades. Caso contrário, o resultado das interações econômicas apresentará ineficiências, como no caso da tragédia do uso comum.

Por essa razão, o autor sustenta que ocorrerá um sobreuso de dado recurso escasso sem um mecanismo que restrinja seu uso, o que pode ser fornecido pela solução privada ou pública, desde que acompanhadas de um sistema jurídico eficiente para garantir a observância das regras. Essas podem ser soluções efetivas em termos de custos para prover o uso eficiente do recurso comum. Enfim, Varian (2003) faz uma formalização do modelo de Hardin (1968), a partir de uma simplificação do texto original, ora seja, restringindo-o a esfera econômica. Todavia, os seguintes contrapontos em relação à interpretação de Varian são pertinentes:

i) o autor supõe que o sistema de DP permite endogeneizar totalmente todas as externalidades, ou seja, controlar todos os comportamentos oportunistas e que este controle não implica em custos, 0 que configura um self enforcement ${ }^{28}$. Todavia, se isto não funcionar, devido à existência de assimetrias de informação, os DP serão parcialmente ineficientes e a implementação desses DP se traduzem por custos positivos. Essas assimetrias da informação são resultantes da reação dos agentes e da individualização das relações no mercado (BOWLES; GINTIS, 1993, p. 7), das especificidades econômicas dos bens, dos serviços e dos componentes qualitativos embutidos neles ${ }^{29}$. Além disso, diante da complexificação dos bens e dos serviços ligados à comunicação e à informação, devido ao intrincado sistema e relações entre seus diversos componentes, não é possível implementar um sistema de DP intelectual privado eficiente: (i) as características de não exclusão dos bens que circulam nas redes não permitem controlar suas diferentes modalidades de apropriação; (ii) não é possível eliminar as estratégias de desvio das externalidades produzidas pelos diferentes componentes do sistema; (iii) as próprias modalidades de valorização ligadas à criação de externalidades de redes atuam no sentido contrário - um sistema de DP intelectual privado limita essas externalidades (POSNER, 2005, p. 69);

ii) de modo equivalente ao explicitado anteriormente para o caso de Hardin, há implicações ligadas à existência de externalidades de redes à la Katz; Shapiro (1985), em que as qualidades indivisíveis do serviço dependem diretamente do número de usuários. Esse ponto é igualmente negligenciado na análise proposta por Varian (2003). Reforça-se a ideia de que em questões que envolvem bens públicos, as modalidades de apropriação privada desses bens provocam falhas de mercado importantes, de acordo com Nelson (2003). Contrariamente, o nível dos custos necessário para controlar e conter os comportamentos oportunistas que se desenvolvem a partir do caráter não rival desses bens é muito alto (DEMSETZ, 1964, p. 16). Para diminuir esses custos a um patamar compatível com a produção de tais bens, a solução consiste em modificar a natureza dos DP intelectual e, possivelmente, a modalidade de governança;

iii) Varian, assim como Hardin, também negligencia a existência dos chamados anticommons. Por exemplo, quando há inúmeros titulares dos DP intelectual necessários à adoção de certa inovação

28 A teoria neoclássica parte do pressuposto segundo o qual há self enforcement, existindo de antemão certas condições gerais essenciais que são asseguradas e funcionam plenamente sem representar nem custo privado nem custo social (HERSCOVICI, 2013). Todavia, contrariamente à hipótese implícita utilizada na construção walrasiana e aceita por Varian, o self enforcement não é nem gratuito nem totalmente eficiente. Ver Bowles; Gintis (1993).

29 Por exemplo, uma determinada marca pode ser concebida como um sinal de qualidade: se, por um lado, os produtos se tornam mais caros, devido aos gastos em publicidade e propaganda, por outro, eles permitem diminuir, para os consumidores, os custos de pesquisa (search costs) por informações relativas a esta qualidade (POSNER, 2005). 
tecnológica, o preço será comparativamente mais alto do que em uma situação na qual há apenas um titular. O desenvolvimento dos comportamentos predadores leva ao aparecimento de externalidades de demanda ${ }^{30}$ : externalidades que produzem falhas de mercado e se traduzem por uma diminuição do bem-estar. Nessa situação, os preços relativos à aquisição da tecnologia são comparativamente mais altos que os preços concorrenciais (HERSCOVICI, 2012a). Privatizar as modalidades de apropriação da produção tecnológica e científica leva ao surgimento dos comportamentos oportunistas e a queda da taxa de crescimento da produção em razão do caráter cumulativo desse tipo de atividade, gerando a ineficiência dos mecanismos de negociação privada (NELSON, 2003) ${ }^{31}$.

Cabe ressaltar, uma vez mais, de acordo com Herscovici (2012a), que a interpretação que Varian (2003) faz da análise de Hardin (1968) é inteiramente neoclássica, mantendo as hipóteses que caracterizam a matriz walrasiana: racionalidade substantiva dos agentes, ausência de incerteza, eficiência dos mercados concorrenciais e self enforcement. Por isso, sua interpretação conclui, equivocadamente, que o mercado é sistematicamente a instância mais eficiente para a alocação dos recursos escassos, maximizando a produção total e minimizando continuamente os custos.

\section{5 - Conclusão}

Pode-se afirmar que as contribuições teóricas seminais desenvolvidas por Hardin (1968) permitiram criar um instrumental de análise microeconômico voltado para o estudo do problema de social choice aplicado ao uso dos bens comuns, aprimorados pelos respectivos avanços teóricos agregados à temática envolvida ao longo do tempo. Como exposto neste artigo, essas novas maneiras de abordar os diversos aspectos concernentes ao tema do sobreuso de recursos escassos podem ser estudadas a partir desses instrumentos. Assim sendo, a partir da apresentação do problema dos commons e do debate teórico advindo do mesmo, cabe ressaltar os seguintes aspectos gerais:

i) para Hardin, a solução para o problema dos commons consiste em implementar um princípio de coerção, em que a propriedade privada do recurso escasso cumpre a função de preservar o estoque disponível de bem comum, evitando seu sobreuso. Ele admite a solução de propriedade comunal, desde que estejam bem definidas as regras jurídicas de acesso e uso do bem comum. No caso específico dos commons envolvendo a população, o autor aponta que o problema somente surge em condições de alta densidade populacional e que a única alternativa é a de renunciar à liberdade de procriar, pois é a alternativa que se tem para a preservação de outras liberdades mais importantes. Como esclarecido, na perspectiva de Hardin, o contexto genérico dessa lógica pode ser expandido a qualquer outra situação de ordem similar, chegando-se a resultados análogos;

ii) na exposição de Varian (2003), que traz um enfoque estritamente econômico da questão dos commons, as soluções sugeridas são fundamentalmente as mesmas apresentadas por Hardin, sendo que os resultados são atingidos por meio de uma formalização algébrica simples. O autor defende que se os DP forem bem definidos, não haverá problemas relativos às externalidades. Caso contrário, o resultado das interações econômicas apresentará ineficiências, como a tragédia do uso comum. Nesse sentido, ele conclui que a solução de mercado é a que leva a um resultado eficiente no sentido de Pareto, pois as ineficiências só podem resultar de situações em que não há meio de impedir que outros utilizem o recurso em questão;

iii) contrariamente a proposta de Hardin, no caso da apropriação privada de bens comuns, existem outros meios para regular o sistema, como as convenções e regras explícitas e/ou implícitas no caso das diferentes coletividades, que determinam e controlam as diferentes modalidades de apropriação social desses bens, o que evita comportamentos oportunistas. Além disso, é preciso, igualmente, diferenciar as situações em função da natureza econômica do bem comum, pois há casos em que os

30 Trata-se de externalidades de demanda no sentido definido pelos novos keynesianos.

31 Esse exemplo é apenas outra forma de representar o caso já descrito na seção 4.1, iii. 
recursos obtidos deles são bens privados divisíveis, enquanto há outros em que são públicos indivisíveis, resultando em distintas abordagens para cada situação;

iv) a crítica feita à proposta de Varian é resultante da base teórica utilizada para sua análise do problema dos commons, qual seja, as premissas provenientes da escola neoclássica. Contrariamente a essa teoria, concebe-se que o problema dos commons deve-se à instabilidade desse sistema, com incerteza forte e desequilíbrio, em que o sistema de preços não tem condições de implementar a regulação de mercado. A proposta de endogeneizar totalmente todas as externalidades, a não abordagem dos commons no contexto das externalidades de redes, a negligência da existência dos chamados anticommons e das assimetrias de informação são elementos que põem em xeque as teses defendidas pelo autor.

Por fim, é oportuno observar que, como visto no decorrer deste artigo, o problema dos commons é bastante atual e complexo, envolvendo várias áreas do conhecimento humano. Assim, não pode ser simplesmente reduzido a um sistema de preço concorrencial que permite alocar recursos escassos, produzir a partir de uma minimização dos custos e alcançar um estado de ótimo social, como comumente é o enfoque microeconômico tradicional. Uma abordagem mais dinâmica permite incluir novos e importantíssimos componentes à discussão, tornando as análises econômicas mais robustas e realistas, o que é uma necessidade frente aos desafios atuais existentes neste campo do conhecimento.

\section{Referências}

ALCHIAN, A. A.; DEMSETZ, H. Production, information costs, and economic organization. American Economic Review, 62, p. 777-795, Dec. 1972.

ALCHIAN, A. A.; DEMSETZ, H. The Property Rights Paradigm. The Journal of Economic History, v. 3, n.1, p. 16-27, 1973.

ARROW, K. J. Limited Knowledge and Economic Analysis. American Economic Review, Mar. 1974.

ARROW, K. J. Social Choice and Individual Values. Yale University Press, 1951.

BATESON, G.; JACKSON, D. D.; HALEY, J.; WEAKLAND, J. Toward a theory of schizophrenia. Behavioral Science, Veterans Administration Hospital, Palo Alto, California; and Stanford University, p. 251-264, 1956.

BARZEL, Y. Economic Analysis of Property Rights. Cambridge University Press, 1997.

BENARD, J. Economie Publique. Econômica, Paris: 1985.

BENTHAM, J. [1789]. An Introduction to the Principles of Morals and Legislation. Oxford: Adamant Media Corporation, 2005.

BOWLES, S.; GINTIS, H. The Revenge of Homo Economicus: Contested Exchange and the Revival of Political Economy. The journal of Economic Perspectives, 7 (1), p. 83-102, 1993.

COASE, R. H. The Problem of Social Cost. Journal of Law and Economics, 3, p. 1-43, 1960.

CONDORCET, N. Essai sur l'application de l'analyse à la probabilité des décisions rendus à la pluralité des voix. Paris: de l'imprimerie royale, 1785. 
COX, S. J. B. No Tragedy on the Commons. Discussion Papers, Workshop in Political Theory and Policy Analysis, Indiana University. 1986.

DARWIN , C. R. [1859]. A Origem das Espécies. São Paulo: HEUS, 1981.

DEMSETZ, H. The Exchange and Enforcement of Property Rights. Journal of Law and Economics, v. 7, p. 11-26, 1964.

FRANKEL, C. The Case for Modern Man. New York: Harper, 1955.

HARDIN, G. The Tragedy of the Commons: the population problem has no technical solution; it requires a fundamental extension in morality. Science, p. 1243-1247, Dec. 1968.

HELLER, M.; EISENBERG, R. Can Patent Deter Innovation? The Anticommons Tragedy in Biomedical Research. Science, v. 29, p. 698-701, 1998.

HERSCOVICI, A. A Economia Neoclássica: uma análise lakatosiana da cheia do mainstream até sua implosão. Revista de Economia Política, v. 35, n. 4 (141), out./dez. 2015.

HERSCOVICI, A. Capital intangível e direitos de propriedade. Revista de Economia Política, v. 27, n.3 (127), p. 394-412, jul./set. 2007b.

HERSCOVICI, A. Direitos de propriedade intelectual e novas formas de governança na economia digital: elementos de análise. 4th ACORN-REDECOM Conference Brasília, May 2010.

HERSCOVICI, A. Escolha Coletiva, Governança e Direitos de Propriedade: uma Análise Econômica dos Commons. Revista Nova Economia, Belo Horizonte: UFMG, v. 23, n. 2, p. 185-208, jan./abr. 2013.

HERSCOVICI, A. Informação, Conhecimento e Direitos de Propriedade Intelectual: os limites dos mecanismos de mercado e das modalidades de negociação privada. Economia e Sociedade, Campinas, v. 21, n. 3 (46), p. 667-694, dez. 2012a.

HERSCOVICI, A. Information, qualité et prix: une analyse économique de l'internet et des réseaux d'échange d'archives. Congrès International Online services ADIS/Université de Paris Sud. Paris, déc. 2007a.

HERSCOVICI, A. Teoria da renda diferencial e heterogeneidade do capital: uma análise neoricardiana. In: VII Encontro Internacional da Associação Keynesiana Brasileira, 2014. São Paulo: Anais do VII Encontro da AKB, 2014.

HERSCOVICI, A. Tragedy of commons versus tragedy of anticommons? An institutional analysis. In: Second WINIR Conference, 2015, Rio de Janeiro. Anais do Second WINIR Conference, v. 1, p. 428, 2015.

HESS, C.; OSTROM, E. A framework for Analyzing the Knowledge Commons, in Understanding Knowledge as a Commons. The Mit Press, Cambridge, Massachusetts, London, England, 2007.

KATZ, M. L.; SHAPIRO, C. Network Externalities, Competition and Compatibility. American Economic Review, v. 75 n. 3, 1985.

KINGSLEY, D. Population Policy: Will Current Programs Succeed? Science, New York: AAAS, v.158, n. 3802, p. 730-739, Nov. 1967. 
LLOYD, W. F. Two Lectures on the Checks to Population.1833.

MAYOS, G. G. W. F. Hegel: vida, obra y pensamiento. Barcelona, Planeta DeAgostini, 2007.

MALTHUS, T. R. [1798]. An Essay on the Principle of Population. London: Malthus Press, 2013.

NELSON, R. R. The Market Economy and the scientific commons. Research Policy, New York (Columbia University), 33 (2004), p. 455-471, Sep. 2003.

OSTROM, E. Private and Common Property Rights, Workshop in Political Theory and Policy Analysis, Population and Environmental Change. Indiana University, 2000.

PINDYCK, R. S.; RUBINFELD, D. L. Microeconomia. São Paulo: Pearson, 2010.

POSNER, R. A. Intellectual Property: The Law and Economics Approach. Journal of Economic Perspectives, v. 19, n. 2, p. 57-73, Spring 2005.

RICARDO, D. [1815]. Essay on the influence of a low price of corn on the profits of stock. In: the works and correspondence of David Ricardo. SRAFFA, P. (Ed.), v. IV, Pamphlets and Papers (18151823). Indianapolis: Liberty Fund, 2004.

RICARDO, D. [1817]. On the Principles of Political Economy and Taxation. London: John Murray, 2012.

SMITH. A. [1776]. A Riqueza das Nações: uma investigação sobre sua natureza e suas causas. São Paulo: Abril Cultural, 1983.

SRAFFA, P. Sulle relazioni fra costo e quantitá prodotta. Annali di Ecónomia, v. II, n.1, 277-328, 1925.

UNITED NATIONS. The Universal Declaration of Human Rights. Paris: UN, 1948.

VARIAN, H. R. Microeconomia: princípios básicos. Rio de Janeiro: Campus, 7ª ed., 2003. 